\title{
Sharing Tacit Knowledge: A Case Study in the Australian Film Industry
}

\section{Irit Alony and Greg Whymark Central Queensland University, Rockhampton, Australia}

\author{
i.alony@cqu.edu.au; \\ g.whymark@cqu.edu.au
}

\author{
Michael Jones \\ University of Wollongong, \\ Wollongong, Australia
}

mjones@uow.edu.au

\begin{abstract}
This paper explores tacit knowledge sharing. This case demonstrates the significance of knowledge sharing to organizational performance, by exploring the contribution of tacit knowledge sharing to the success of projects in the Australian Film Industry (AFI). The differences between knowledge sharing, collaboration and communication, and their interrelations are addressed. We also explore the concepts of knowledge, information, and data. In the interchanges reported here the knowledge shared is almost entirely tacit, and the "raw" data and information do not exist without the context that makes them knowledge. The paper includes the identification of many factors affecting knowledge sharing, not all of which have been identified by previous researchers. This research contributes to a better understanding of tacit knowledge and how that knowledge is shared. This in turn contributes to a better understanding of how knowledge management can be supported in a modern organization, where often the technology is used in ways not well understood by system managers and software developers. A better understanding can lead to better ICT design and support of knowledge sharing both within and across organizations.
\end{abstract}

Keywords: Knowledge Sharing, Film Industry, Tacit Knowledge, Qualitative, Collaboration.

\section{Introduction}

This paper reports research that has been conducted as part of a larger study into the organization and management of the Australian Film Industry (AFI) (Jones, 2005). During that study the data collected indicated a flow of knowledge, and in particular what appeared to be tacit knowledge. The issue of knowledge sharing versus communication was also raised by the case study. Hence, the AFI is an ideal case study to use to examine the factors enabling the sharing of knowledge in general, and of tacit knowledge in particular.

In their study of the literature on knowledge sharing Alony and Whymark (2006) described the

Material published as part of this publication, either on-line or in print, is copyrighted by the Informing Science Institute. Permission to make digital or paper copy of part or all of these works for personal or classroom use is granted without fee provided that the copies are not made or distributed for profit or commercial advantage AND that copies 1) bear this notice in full and 2) give the full citation on the first page. It is permissible to abstract these works so long as credit is given. To copy in all other cases or to republish or to post on a server or to redistribute to lists requires specific permission and payment of a fee. Contact Publisher@InformingScience.org to request redistribution permission. many factors reported in previous research, and identified the need for an integrated model of knowledge sharing. As that report highlighted, the literature has yet to describe all the factors influencing knowledge sharing, and has yet to describe how these factors interact with each other. There are many reasons for this, not the least including the complexity of knowledge worker relationships, the influence of organizations 
themselves, and the need to better understand the nature of knowledge.

In the context of this larger problem, this paper considers the flow or sharing of information between a select group of knowledge workers, professionals and artists who participate in the Australian Film Industry. Alony and Whymark (2006) reported on the observed factors that affect knowledge sharing, and that paper provided a comprehensive description of the factors that previous researchers had identified. In this paper we examine which of those factors can be observed amongst this particular group of workers. We therefore only describe the factors observed, and unless relevant for other reasons, do not refer to factors described elsewhere.

Knowledge sharing in organizations is of great interest to researcher and practitioner alike. Both report that knowledge sharing improves organizational performance (Lesser \& Storck, 2001), promoting competitive advantage (Argote \& Ingram, 2000), organizational learning (Argote, 1999), innovation (Powell, Koput, \& Smith-Doerr, 1996) and even survival (Baum \& Ingram, 1998). To argue that premise is outside the scope of this paper, but even if not universal, many managers ask how their organization can promote knowledge sharing amongst their knowledge workers.

This paper assembles factors reported to affect knowledge sharing, and through interviews and content analysis examine the nature of their effect in the AFI. Much of previous research has focused on empirical evidence (Burt, 2004; Cross \& Cummings, 2004; Cummings, 2004; Hansen, 1999, , 2002; Levin \& Cross, 2004; Owen-Smith \& Powell, 2004; Reagans \& McEvily, 2003). Exploratory qualitative research has been reported (Ardichvili, Page, \& Wentling, 2003; Cummings, 2004; Dyer \& Nobeoka, 2000; Stenmark, 2000) in an attempt to identify and describe factors affecting knowledge sharing. In this paper, we describe factors previously identified that may impact on the question: how does knowledge sharing happen?

Markus (2001) defined four types of knowledge reusers: Shared work producers, shared work practitioners, expertise seeking novices, and secondary knowledge miners. The concept of knowledge being a collaborative, or group, event is relevant to the AFI and the observations in this particular study support the concepts of the "shared work producers" and the "shared work practitioners" depicted by Markus. In particular, in this paper we study the information flow between participants, looking for knowledge sharing events.

This leads to the research objective of this paper which can be described using the following three questions.

1. What is the nature of knowledge sharing in the Australian Film Industry? Is it tacit or explicit knowledge that is shared?

2. What is the difference between information flow and knowledge sharing?

3. What factors either enable or inhibit this sharing of knowledge?

Why use the AFI for this research? The AFI is relevant as it illustrates the characteristics of a typical project environment. Film work is highly reliant on knowledge sharing for its success. The work is executed in highly stressful conditions. There is little tolerance for mistakes and little allowance for remedial work. The goals achieved by the AFI indicated knowledge sharing is successfully accomplished. This study therefore undertakes to examine why and how. This case study also provides further understanding of the mechanisms that are at work when knowledge workers work collaboratively.

This case study demonstrates the importance of knowledge sharing. Technology is not specifically addressed, but as it is ubiquitous in modern organizations, technology needs to support not only explicit knowledge sharing (Majchzak, Rice, King, Malhotra \& Ba, 2000) but also tacit 
knowledge sharing. This paper highlights the factors that need to be considered when planning and designing technological tools to provide effective support this important activity.

The following sections describe the AFI environment, the method of data collection, and the background of the participants. We then discuss communication, knowledge transfer and collaboration, and the differences between them. The factors enabling or inhibiting the process are identified, and discussed by category. The paper concludes with suggestions for future research as a result of this investigation. This discussion begins with a brief introduction to the Australian Film Industry.

\section{Background of this Study}

\section{The Australian Film Industry (AFI)}

Film production, in Australia and around the world, began in the confined and regulated context of a conglomerated industry. Production companies grew which were largely vertically integrated with each factory being an independent, self-sufficient unit (Billups, 2003). Today these production companies provide nothing more than a name and in some instances project finance (Billups, 2003; Jacka, 1997).

The Australian industry followed in the shadow of Hollywood. In the late 1940s, the large prewar companies began breaking up to become smaller specialist enterprises who combine on a project-by-project basis to produce a film, and then disband in search of the next opportunity (Jacka, 1997). There are similarities with knowledge workers in other industries, especially those that work in a project management or consulting environment, but these are the subject of further research.

This change in industry structure has bred a new type of employee, one who has no stable employment and no guarantee of income; working from project to project, company to company in search of payment or training, the two often being mutually exclusive (Arthur \& Defillippi, 1998; Blair, Grey, \& Randle, 2001; Daskalaki \& Blair, 2002). The plight of these casualised workers (Fairfax, 2003) is exacerbated by the difficult environment of their 'industry' which works to further constrain and complicate their work situation (Emery \& Trist, 1965). In this new working environment, knowledge is bound to each worker, there is no central repository within which workers can deposit and extract information relative to their work. There is therefore a great reliance on collaboration, communication and knowledge sharing.

The industry employs a large number of people and provides significant income to Australia's economy. It employs more than 16,000 people in 2,174 businesses, and generates almost 1.6 billion Australian dollars per year (Australian Bureau of Statistics, 2003)

The AFI is made up of a variety of diverse firms many of which are very small (less than $25 \mathrm{em}$ ployees) (Australian Bureau of Statistics, 2003). These firms operate in a turbulent organisational environment context (Emery \& Trist, 1965), where work units regularly experience a high number of exceptions or unanticipated situations and frequent challenges and problems.

An environment of this nature results in the formation of what Perrow (1967) refers to as nonroutine organisations. Perrow puts this down to a combination of high task variability and difficult problem analysability. In sum, the Australian Film Industry is an industry which faces rapid and constant change. The Australian Film Industry presents a challenging industry, both to study and to work in, and this makes it particularly interesting as an environment in which to study knowledge sharing. 
Current managerial and organisational research has tended to bypass this area of business with only a few research programs taking any interest (Blair, 2000; Cunningham, 2002; Starkey, Barnatt, \& Tempest, 2000).

There is a clear need to study the Australian Film Industry, especially from the perspective of understanding what causes the industry to work so well given all of the difficulties and constraints. There is also a need to share this unique organisational environment with other researchers, and practitioners in other fields. The tensions caused by the change in work practices, the change in technology, and the lack of large corporate ICT infrastructure make the AFI an ideal candidate for the study of knowledge sharing, and the mechanisms that operate to facilitate knowledge sharing in that industry. The Australian Film Industry is a rich area for discovery and analysis.

\section{How the Data Were Collected}

In this study the perception of the respondent is the unit of analysis. Further, the respondents are not asked to discuss knowledge management and knowledge sharing directly, but rather are led to discuss how collaboration and skill sharing occurs in their industry. The data were collected as part of a larger study into the organization and management structure of the AFI. In this report the data are analysed for evidence of knowledge sharing and the enabling and inhibiting factors surfaced by the description of knowledge sharing events provided by the participant interviews.

A series of research interviews were held with Film workers during the period from September, 2004 to March, 2006, comprising seven interviews in total. Table 1 lists all of these interviews. Selection of the first two participants was based on a referral from the University of Wollongong's film office (Film Illawarra). After these initial interviews subsequent selection of participants was based on referrals and theoretical sampling (Glaser, 1978), which meant that people were only selected if they could add value to the study.

Table 1. Table of Transcripts Used

\begin{tabular}{|c|c|c|c|c|}
\hline Interviewee & Profession & Type & Date of Record & Pseudonym/ Citation \\
\hline 1 & Producer & Interview & $1^{\text {st }}$ September 2004 & (Jim-Producer, 2004) \\
\hline 2 & Producer & Interview & $1^{\text {st }}$ September 2004 & $\begin{array}{l}\text { (Sara-Line-Producer, } \\
\text { 2004) }\end{array}$ \\
\hline 3 & Producer & Interview & $14^{\text {th }}$ October, 2004 & (Phil-Producer, 2004) \\
\hline 4 & Producer & Interview & $14^{\text {th }}$ October, 2004 & (Alice-Producer, 2004) \\
\hline 5 & $\begin{array}{l}\text { Production } \\
\text { Manager }\end{array}$ & Interview & $24^{\text {th }}$ February, 2005 & $\begin{array}{l}\text { (Vera-Production- } \\
\text { Manager, 2005) }\end{array}$ \\
\hline 6 & $\begin{array}{l}\text { Production } \\
\text { Manager }\end{array}$ & Interview & $4^{\text {th }}$ March, 2005 & $\begin{array}{l}\text { (Lyn-Production-Manager, } \\
\text { 2005) }\end{array}$ \\
\hline 7 & Gaffer & Interview & $10^{\text {th }}$ March, 2005 & (Simon-Gaffer, 2005) \\
\hline
\end{tabular}

The first two interviews were held on the same day with two film producers in two separate locations. These initial interviews went from 90 to 120 minutes each, and both yielded excellent, rich information. After these two, the interviews became progressively shorter as the study progressed, with the final interviews running just short of one hour each. Glaser and Strauss (1967) explain that it is customary for interviews to run this way: 
At the beginning of the research, interviews usually consist of openended conversations during which respondents are allowed to talk with no imposed limitations of time. ... Later, when interviews and observations are directed by the emerging theory, he can ask direct questions bearing on his categories. ... Thus, the time for any one interview grows shorter as the number of interviews increases.

It was decided to commence with producers because it is the producer who actually manages the set. Therefore, these people are usually in a good position to provide an overall picture of film management and the associated problems and processes, especially with regard to knowledge sharing and collaboration.

Interviews were based on open-ended questions which allowed for significant prompting and focussing. Table 2 provides a sample of these questions. They varied slightly with each interview according to the direction the interview went, and the information that was provided. It was also intended that the questions would change over time as the data accumulated into categories. It is important to note that the interview protocol did not specifically ask questions about knowledge sharing. The analysis in this paper is carried out on the stories of collaboration that the respondents tell.

Table 2. Initial Set of Questions

\section{OPEN-ENDED QUESTIONS.}

1. In your opinion - what makes a good film?

This is a broad question, which includes all aspects of production, including creative. Through this question I am hoping to get a sense of where this person stands, and their possible influences/biases. [As well as a few leading comments.]

\section{What is the most difficult/critical aspect of filmmaking?}

If necessary prompt with: scheduling - budgeting - communications - cast/crew relations - production management

This is a very direct question, I am hoping to learn what areas of the process this person finds impacts the most on the production process, which may lead me to other areas for analysis/focus.

3a. What was the most difficult film you had to manage?

3b. What made it so difficult?

4a. How much reliance does your position or function place on management experience or knowledge?

4b. Which of these skills do you feel is required most?

4c. Do you think any of these skills need strengthening?

I am hoping to learn about some of the more obvious and acknowledged management problems, this may also steer me in a new and more focused direction.

5. Are there skills unique to the function of $<$ producer $>$ that are difficult, or rarely, attained?

This is to validate the findings from above.

6. How does the relationship between you and the production company/studio/investors/sales agents etc affect your ability to complete the film efficiently/effectively?

This question asks the extent to which the producer has his hands tied by the 'others', those external to the production. 
During the interviews a digital voice recording was made, along with notes which enabled the recollection of certain expressions and body language that would convey information pertinent to the participants' intended meaning. For example, in response to a question on the importance of communication, Sara responded by saying:

Um, I think communication is a really, really important skill. And a lot of ... I mean I'm not going to claim that most producer's don't have that, but I think being able to talk to people on a human level is vital and to listen to what people say. I mean that's one of the main skills of producers. Listening to what everybody has to say... (Sara-Line-Producer 2004).

During this part of the conversation Sara became very animated, she raised her voice a little, and made more direct eye contact. This was interpreted to mean that this aspect of her job was very important to her. Similar notations and allowances were made through all of the interviews to enable an accurate record of all information that was conveyed during the meeting. This is similar to what Glaser terms as listening "with a big ear", meaning not to preselect or filter information (Glaser, 2001).

Analysis was undertaken using qualitative data analysis software. Analysing qualitative data is often seen as a demanding, repetitive and arduous task (Basit 2003, p. 143). Although predominantly a mechanical exercise, it requires an ability of the researcher to be dynamic, intuitive and creative, to be able to think, reason and theorise (Basit 2003, p. 143). The goal of qualitative analysis is to deconstruct blocks of data through fragmentation and then have them coalesce into collections of categories which relate conceptually and theoretically, and which make assumptions about the phenomenon being studied. Richards (2002) calls this process "decontextualizing and recontextualizing" and regards this as the fundamental process of qualitative data analysis.

Qualitative data analysis uses a process of reduction to manage and classify data (Tesch, 1990). In this process, units of text are first de-contextualised by removing them from their source - with their meaning intact - and then re-contextualised by drawing from them a more robust, context independent meaning based on an accumulation of evidence.

The ability of the researcher to code is an important part of analysis (Basit, 2003, p. 144; DeNardo \& Levers, 2002, p. 4). It involves the researcher in two ways. Firstly, the data must be divided into meaningful textual segments which are logical and which add value to the research. Secondly, a tag or label must be attached to the data which is descriptive and sufficiently abstract to encompass other similar, yet unique, datum (Glaser, 1978).

The data collected in this research project were analysed using a program called NVivo ${ }^{\mathrm{TM}} 2.0$ (QSR International Pty Ltd, 2002). This software provided invaluable assistance. Data were coded more generously than would be achieved with 'paper and pen' methods, and while this most probably led to over-coding (this is a problem reported by Blismas and Dainty (2003, p. 460), it allowed ideas and issues to emerge more freely without the compulsion to force data into already established categories.

\section{Tacit Knowledge}

"Explicit" or codified knowledge refers to knowledge that is transmittable in formal, systematic language. On the other hand, "tacit" knowledge has a personal quality, which makes it hard to formalize and communicate. Tacit knowledge is deeply rooted in action, commitment, and involvement in a specific context (Nonaka, 1994, p. 16)

Knowledge management literature describes, identifies and measures the sharing of explicit knowledge. As a result of this, research has emphasized two areas of difficulty with regard to 
tacit knowledge. Firstly, tacit knowledge is very difficult to identify in the practical sense, and secondly, it is equally, if not more, difficult to isolate instances of tacit knowledge sharing as this discovery requires an explication of the tacit knowledge.

The conditions in AFI prevent the creation of explicit knowledge repositories. Knowledge is bound within the worker, and often difficult to formalize. It is rooted in the action of creating the project's product. The knowledge shared is clearly tacit knowledge. The following quote clearly describes both the nature of tacit knowledge sharing and its extent within the AFI. In order for people to work together on a film set there is a great deal of reliance on knowledge sharing.

\begin{abstract}
a perfect example is probably ah, a costume designer going to a designer, and saying "what colour are you going to paint that wall in the set, because I really want her to wear this dress..." and he'll say "Oh I'm going to paint it orange" and she'll say "this dress is perfect for the sequence, absolute perfect for the sequence, and it won't look good against that orange wall." And that is the sort of collaboration you have to have, I mean these are all incredibly talented, highly volatile, very creative people and um, they've all got a vision but as long as they've all got the same vision then it works, and that's a really great thing about having people who've worked together before. And so they have to come to a compromise, it's not my decision about whether the wall's orange or the frock's yellow, it's um, what they think, what they can make work and who collaborates with whom in order to..., if one has to give up a colour then which is the most important, is the character of the girl in her frock of the most importance or is the nature of the house in which the man lives colouring his character? (Alice-Producer, 2004).
\end{abstract}

The above quote may be seen as either information sharing or knowledge sharing. Nonaka's perspective is that the message itself may appear to carry mere facts or information. However, the content exists in a wider context and when interpreted or internalised makes this information knowledge (Nonaka, 1994).

While the importance of user participation in the development of systems is addressed elsewhere (Terry \& Standing, 2004), the examples in this paper help to illustrate the role of the user's view and communication of their requirements plays in how they perceive the success of a project.

Communication and knowledge flow are inextricably linked. The following analysis will show that the communication of information is embedded in the contextual use and perceived value of that information, making it knowledge by any definition (Alony \& Whymark, 2006). Further, we will claim that most of the observed data resulting from this case study of the AFI were evidence of tacit knowledge and tacit knowledge sharing.

\title{
Evidence of Knowledge Sharing
}

\section{Measuring Knowledge Sharing}

The different ways of operationalizing knowledge sharing can be divided into the following categories: based on amount, events, receipt of useful knowledge, and result-based assumption. These categories are fully described elsewhere (Alony \& Whymark, 2006). Cross and Cummings (2004) make a result based assumption and claim "job performance in knowledge intensive work is, to some degree, a product of obtaining the right information" (Cross \& Cummings, 2004, p.4). They thus treat individual performance as a surrogate measure for effective knowledge sharing. The analysis of data in this study takes the same perspective. That is, this study views the success of workers' and work units in the AFI to be an outcome of effective sharing of knowledge. In this study, the investigation focuses on the knowledge sharing event as the unit of analysis. Further, 
the event is analyzed as it is described by a member of the sharing group, and so it is a study of the perceptions of the knowledge exchanger.

\section{Collaboration or Just Communication}

What is the difference between knowledge sharing, communication, and collaboration?

The data shows occurrences of knowledge sharing, collaborative knowledge building, and communication. Sometimes it is simple to define which activity is taking place. A clear example of communication, but no collaboration, between the production manager and the producer is:

the production manager will say "I've moved ten thousand dollars out of that area and l've put it there, and l've put it there, and l've put it there.

This is why." And I say great, terrific, carry on...(Phil-Producer, 2004).

In the example, the nature of the knowledge exchanged is information regarding the location of funds, and the reason behind the change of this allocation. Information (and perhaps knowledge) exchanged hands, when the sender of the information being active and the receiver being passive in the process of accepting the information.

An unambiguous example of tacit knowledge transfer can be found in the following quote, of a producer getting a call from another producer, who works on a different project, asking for advice.

Someone ... was worried about project she's on, and she said "The set decorator hasn't chosen lights so they won't get the set ready for Tuesday" and she said "now, what should I do?" I said "ok well you've got to do this, this and this tomorrow and you can't not be ready to film" (VeraProduction-Manager, 2005).

An example of collaboration can be identified in this description.

I said to the Director after I looked at it [the location]: "I think this film desperately needs a studio build, because [many different reasons], and she said "look I couldn't agree with you more, but we haven't got the money have we?" and I said "we absolutely don't have the money but if we think that's our priority then we've got to go through the script from scene one to the end, and discuss every little element of it",... And we did that little bit by little bit the whole way through just to find the money so we could build the interior, and a lot of the film was set in the interior of this house and in the end I think it was definitely the right decision to make it, ... many wouldn't see that decision that you could take that budget and say 'yep, we'll do that' (Jim-Producer, 2004).

These examples illustrate the dilemma in trying to identify knowledge in an objectivist way. Such attempts to identify and classify often lead the researcher into considering explicit knowledge that has been decontextualised. If we take Alavi and Leidner's perspective (2001), all of the above examples are knowledge sharing. By taking the constructivist view and using the participant perspective of the sharing event as the unit of analysis, we believe that a richer, more context sensitive, analysis can occur. Consequently, in this paper communication and collaboration are regarded as knowledge sharing activities. Knowledge exchanges hands during the process of collaboration.

Knowledge sharing can be characterized by the transfer of a complete chunk of knowledge from one person to another. The sharer is not necessarily involved in the task for which the knowledge is required, and does not necessarily have interest in its success. In collaboration, however, the roles of "sharer" and receiver are constantly interchanging. Both sides are actively involved in the task, and are likely to aim for its success. 
This is not the first time collaboration has been regarded as a knowledge sharing activity. In their study of Toyota's suppliers network, Dyer and Nobeoka (2000) referred to collaboration as one of the events indicating the occurrence of knowledge sharing. The continued exchange of knowledge by independent agents is an example of what Kilduff and Tsai (2003) identified, that mutual exchange of knowledge increases motivation to share. Collaboration is an active, mutual process, and therefore possibly the reason why there is such a successful knowledge sharing in AFI.

\section{What Does Theory Predict?}

According to social constructivism theory individuals construct their own reality. Knowledge sharing events, as experienced by AFI members, represent this reality. Therefore they are valid examples of knowledge sharing in this analysis.

In the social constructivist paradigm which guides this paper, we are presenting the perceptions of the participant. The number of factors identified by other authors is very extensive, and is described elsewhere (Alony \& Whymark, 2006; Lichtenstein \& Hunter, 2006). Further elaboration of these factors is not provided here.

Evidence of the existence of these factors was found when analysing the transcripts from the AFI case study. The results are reported in six subsections, grouping the active factors under the headings of Individual, Network, Knowledge, Relationships, Organizational and Trust. How these many factors are related is briefly addressed in the seventh subsection - Relationships Between Factors. It is apparent from these data, and elsewhere, that this is a much larger question in need of further research.

\section{Individual Factors}

\section{Position of individuals in the network}

Centrality played an obvious role in the AFI. The producer has a central role, demonstrated in the following quote:

One of the roles of the producer, a key role, $\ldots$ is that the one person who can see the whole picture, with all of the different departments, some cocooned or some interrelating with certain areas, but not with others, and making sure that everybody in fact is working for the same film, but working effectively and coordinating and communicating well with everybody in an area. (Jim-Producer 2004)

The position of individuals involved in knowledge sharing has been found to affect knowledge flow and availability. One dimension of the individual's position is "betweeness centrality" - the number of ties one has, connecting otherwise disconnected individuals. This factor positively impacts the effectiveness of knowledge sharing. Burt found individuals bridging across "structural holes" and who discuss ideas with their contacts are more likely to derive useful solutions for the organization.

Betweeness centrality was found to positively affect individual's performance according to Cross and Cummings (2004). Two types of betweeness centrality were examined: on the information network and on the awareness network. Both were found to positively affect individual performance: the individual's betweeness centrality on the information network provides better access to useful information, whereas the individual's betweeness centrality on the awareness network improves the individual's opportunity to learn who has relevant knowledge. Brauner and Becker (2006) labelled the latter "meta-knowledge" - knowledge about the knowledge of others. The producers describe a need to be in a central position on the awareness network, so that information can pass through them. The hierarchical structure of the production team puts producers in 
this position of bridging across holes. This bridging enables the producer to control the knowledge flow between those teams, as the following quote demonstrates:

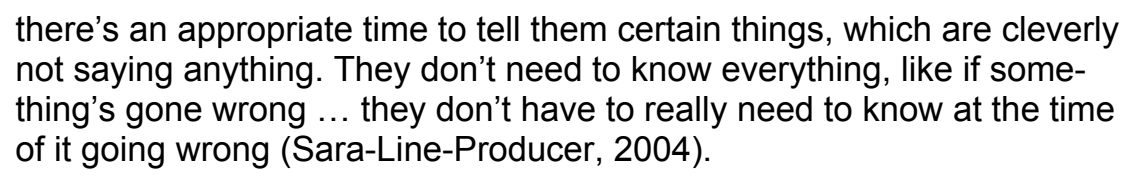

In their research of knowledge spillovers in the Boston biotechnology community, Owen-Smith and Powell found betweeness centrality to have two potential courses of action: a positive one, acting as "cupids [to] pass information on to the distantly positioned networks alters", or, as the members of this network are often more competitors rather than co-operators, a negative one, where "powerfully positioned middlemen extract value by interrupting or distorting information" (Owen-Smith \& Powell, 2004, p. 16).

Research to date makes it clear that a centrally-positioned individual has a better performance due to information flow and availability. The difficulty in measuring these concepts is acknowledged, with a number of surrogates used buy other researchers. In an attempt to measure information flow and availability empirically, there has been no evidence to indicate one surrogate would be more suitable than others. These factors are fundamental to knowledge sharing, and further research is warranted. In this case a more holistic view can be used to imply personal performance from observable organizational performance. The performance in this case is indicated by the final outcome of the production process: the film. The fact the AFI is a successful industry is a surrogate for individual performance in this case.

\section{Network Properties}

The properties of the network, across which knowledge is shared, has been found to have an affect on the sharing process. Two properties that have been recognized to affect knowledge sharing are cohesion and diversity.

Cohesion is defined as the number of strong ties around a strong tie. Reagans and McEvily (2003) explain the effect of network cohesion is by reputation - the existence of more third-party ties around a person promotes sharing information regarding the person and their willingness to assist in the process of knowledge transfer.

Cohesion is found in the AFI. The network appears to be closely interconnected, as demonstrated in the following quotes:

(Phil-Producer 2004) you can always find quite a lot of camaraderie between actors and between crew members, most of whom will know each other

(Phil-Producer 2004) there's a close knit group of people working very closely together

(Lyn-Production-Manager, 2005) if they see your name on a film they know you've worked with them, there is so much not published referee calling going on, whose doing what, where,

(Sara - Line producer 2004) word gets around in [this] industry, it's a word of mouth industry

Diversity of network members was found by Cummings (2004) to positively affect knowledge sharing. Four kinds of diversity were studied by Cummings: Demographic diversity (as in, age, sex and years in the company), geographic diversity (member's location), functional diversity (assignment to work groups) and reporting managers (managers the members report to). A film 
production team is composed of many people with different skills, as well as different backgrounds, as illustrated in the quotes below.

(Sara - Line producer 2004) you have to oversee the whole thing and have knowledge of every process ... Like you have to have knowledge of what the camera department does, the designers, the editors, the accountants... you have to have knowledge of all of that. That's the important thing. To have a thorough understanding of what every role does, and how they work with each other.

(Lyn - Production-Manager 2005) Everybody in the film industry can have varied backgrounds, it doesn't matter what boys club you went to or what school you went to, what uni you went to, because the common goal is the film.

However, the limitations of diversity were also indicated, when a production manager explained why she chose not to work on a film:

(Vera - Production manager 2005) it was a really interesting script too, but not enough money and I think it would be a struggle if only say two of us who really have English as a first language.

This quote shows there is such a thing as "too diverse".

\section{Properties of the Knowledge Shared}

Other than the properties of the knowledge-exchanging parties, the object exchanged also has an effect on the knowledge sharing activity. The level to which knowledge is "codified" or "explicit" makes a difference to how easy it is to transfer knowledge. The terms "codified" and "explicit" are used interchangeably in the research literature.

Earlier in this paper, we demonstrated the tacitness of the knowledge shared in this case study. Colour coordination and knowledge of how reality will appear on screen are, in this example, tacit forms of knowledge.

Hansen (1999, p. 100) found that transferring "highly codified and stand-alone" knowledge over weak ties promotes project completion, and that the transfer of "non-codified" knowledge is more effective over direct ties (Hansen, 1999). The results of Reagans and McEvily (2003, p. 261) are similar. They found "strong ties facilitate the transfer of tacit knowledge more than...codified knowledge". Most of the knowledge transfer observed in this study of the AFI is tacit, and it is therefore expected that strong ties would enable transfer.

\section{Relationships \& Ties}

Knowledge sharing can occur over dyadic relationships. The ties over which knowledge is exchanged have been found to impact on the activity of knowledge sharing.

\section{Tie strength:}

(Sara - Line producer 2004) you're going to have to be working very closely with this person for a number of years (producer says about working with the director)

(Lyn - Production-Manager 2005) you get very close to people who you work with, you form very strong bonds, more than the average people who work in an office environment do because you spend so much time together 
(Sara - Line producer 2004) very often, you know, people will work with people they've worked with before if they've had a good experience, and people like to build up those relationships and that's a really important part of film-making; developing those relationships over the years.

Reagans and McEvily (2003) found that both tacit and explicit knowledge are easier to transfer over strong ties. Hansen (1999), however, found tacit knowledge is easier to transfer over strong ties, but weak ties are more efficient when it comes to explicit knowledge sharing. A lot of the knowledge transferred in AFI productions is tacit, as no repositories of knowledge have been observed or mentioned during the interviews. Therefore, it would be reasonable to expect strong ties to be prevalent in the team environment.

Hansen measured tie strength by asking respondents about relationship-closeness and frequency of communication with each contact. Reagans and McEvily (2003) also asked if the relationship is described as "friendship" or "advice source", to control for the content of the ties. More dimensions of "tie strength" have been described during the interviews:

- Duration of interactions : "really tight ... long hours", "you spend so much time together", (Lyn - Production-Manager 2005)

- Duration of relationship: "developing those relationships over the years", " for a number of years", (Sara - Line-Producer 2004), "if you work well with people you seem to work with them again and again" (Phil-Producer 2004)

- Exclusivity of relationship: "when you are on a film there is not a break" "Your friends don't see you for a long time. And you don't see many of your friends and family", (Vera - Production-Manager 2005)

- Intensity of relationship: "working very closely", "very strong bonds", (Sara - LineProducer 2004)

\section{Tie range:}

(Vera, a production manager, is currently not working. She is outside a project's network) I had a call last night my friend is having problems with a film, she is asking me "what shall I do"

Tie range is defined as ties spanning beyond production unit and is another factor positively affecting knowledge sharing (Cross \& Cummings, 2004). These ties are potentially a source of nonredundant information (Cross \& Cummings, 2004; Hansen, 1999, 2002; Reagans \& McEvily, 2003). Like the quote above, occurrences of knowledge sharing across productions have been mentioned by the participants. However, in the AFI environment, it is difficult to draw the lines of the unit or the organization. The 'frock' quote in the introduction shows collaboration of people from different units in the organization, which shows these collaborations are beneficial, if not crucial, to the success of the project. Nonetheless, it is difficult to draw the line and define where the organization boundary is. If the production is considered an organization, then members are simultaneously involved in more than one production unit at a time. Members are influencing knowledge flow in other units often, and the ties can therefore be considered as intrinsically spanning tie range. These ties may be very enriching and could be a contributor to the success demonstrated by AFI.

\section{Common knowledge:}

Reagans and McEvily (2003) found a positive relationship between the level of common knowledge and ease of transfer. The level of common knowledge was estimated based on the assump- 
tion that individuals from similar background (race, sex, level of education, tenure) and area of expertise would have "common experiences, resulting in shared knowledge" (Reagans \& McEvily, 2003, p. 250).

(Sara - Line producer 2004) Most people in the government funding bodies here are film makers themselves. They've been film makers and independent film makers.

In the quote above, Sara was explaining that the government funding bodies are able to assist filmmakers, due to their knowledge of the filmmaking process.

Cummings' results (described above) are somewhat contradictory to those of Reagans and McEvily (2003). Cummings shows diversity promotes effective knowledge sharing. Reagans and McEvily show the importance of common experience. There is no explanation for this apparent contradiction, but it is probably a result of the shortcomings of the survey research approach. A possible explanation is, different people commonly have different meaning for the same term (for example, the term 'goal' can mean different things to different people, even if they share the same work place). When people are aware of the possibility of such a difference in meanings, they address it. It is therefore possible that they perceive the communication in these cases as more difficult, but it turns out to be more effective. This explanation is supported by the following quote:

(Sara - Line producer 2004) it's comforting to have differing opinions, it is. And quite often having to fight for something that you think's important to your film is actually a really interesting process. Because maybe it makes you realize that actually "no it's not that important to do it this way, this could be a better way to do it", or it makes you realise "yeah, this is actually the best way to do this", and you may be clearer about that.

\section{Organizational Properties}

Since each organization has its own culture, processes, objectives and goals, it can be expected that the nature of knowledge sharing will thus be different and will depend on organizational characteristics. The only organization factor identified so far by research is the existence of incentives to share knowledge.

(Sara - Line producer 2004) they [producers] would earn more working in McDonald's per hour if they worked that many hours, over the counter. Most films I've worked on have always had tight budgets and have always had people putting in ... a lot more time and effort than they get paid for.

Organizational incentives to share knowledge have been found to affect motivation. Bock and Kim (2002) found financial incentives to induce a negative attitude towards knowledge sharing. Dyer and Nobeoka (2001) showed non-financial incentives improve knowledge sharing across organizational boundaries. AFI follows the same principles. The motivation for good knowledge sharing and collaboration is not financial, but rather the reputation of an individual, as can be shown in the following quote:

(Phil-Producer 2004) someone who enjoys telling half truths to their colleagues in order to stir up this or gain an advantage, they stand out. People who've been in that kind of way find themselves pretty short of work.

More research is required to identify other organizational factors, as it is expected that more of them will emerge.

\section{The Issue of Trust}

Trust is manifested in many forms when knowledge sharing is studied.

Ardichvili et al. (2003) have conducted an exploratory research, to identify what impedes personal motivation to share knowledge over an online forum. The study identified trust as an impor- 
tant factor. A description of two kinds of trust in this research complies with the definitions of both kinds of trust measured by Levin and Cross (2004): benevolence-based trust and competence based trust. Benevolence-based trust means "trust that the other members will not misuse the posted information". Competence-based trust means "trust [the knowledge source] to be a source of reliable and objective information" (Ardichvili et al., 2003, p. 72).

As the producer you really have to hope that you've made yourself sufficiently available and sufficiently trusted that people will come to you and will give you an honest account of what the problem is. (Phil-producer 2004)

In accordance with (Lichtenstein \& Hunter, 2006) "s "receiver based" perspective, the producer in this quote aims at making himself trusted by potential sharers, by communicating benevolencebased trust.

Based on the empirical work of McAllister (1995) and Mayer (1995), Levin and Cross (2004) describe trust as a multidimensional characteristic. Two components of which are benevolencebased trust and competence-based trust. Levin and Cross showed that these dimensions of trust have a positive influence on knowledge transfer. They also showed that trust is "a critical mechanism underlying the knowledge benefits of strong ties" (Levin \& Cross, 2004, p. 1486).

When I was younger I would have gone with the people I work with more because it's easier to learn, when you're working with people you're comfortable with, because you can ask the stupid questions. (Lyn - Production-Manager 2005)

This quote shows a link between having benevolence based trust and competence based trust. The production manager, reflecting back on her experiences and learning trajectory, indicates that benevolence-based trust in her surrounding was required for her to be able to gain competence, and therefore gain competence-based trust. The two dimensions of trust therefore appear to be interrelated.

The next section of this paper will elaborate upon the inter-relations between the factors discussed in the preceding section.

\section{Relationships between Factors}

Relationships between factors are an important issue, but are not explored here in detail as they will be the focus of further research. As the data were analysed it became apparent that there are complex relationships between the many factors involved, but the evidence is not conclusive and only possible relationships are suggested at this stage. The whole concept of factors relating to other factors enabling knowledge sharing is in need of major research. Some of the inter-relations observed in this case study are described below.

Diversity and common knowledge. As previously discussed, common knowledge is necessary to enable effective knowledge sharing. At the same time, diversity contributes to the effectiveness of knowledge sharing. The benefit of diversity has been explained so far by the non-redundancy of the knowledge it brings with it. However, another possible explanation emerges from the data: diversity promotes clarification of ideas. In the absence of diversity, the sharer might assume preexisting understanding. By clarifying ideas, the sharers themselves get a better understanding. This also prevents misunderstandings with the receivers. This might be perceived as a longer and a more difficult process, but it provides greater benefit than sharing knowledge when there is presumed shared understanding.

Knowledge type and tie strength. Hansen $(1999,2002)$ showed strong ties are more beneficial for the sharing of tacit knowledge than weak ties. As sharing tacit knowledge is more difficult than sharing explicit knowledge, the conduit of a strong tie provides better motivation for the ac- 
tivity. The producers and managers in the AFI are constantly striving to achieve stronger relationships among their teams, with the intent to ease the process of sharing knowledge.

Cohesion and trust. Cohesion promotes better behaviour which promotes benevolence and competence based trust. The fact that individuals know that their actions are transmitted to the entire knowledge sharing network motivates them to perform better. They are more motivated to advance both their competence based and their benevolence based trust, in order to continue their employment in the field.

\section{Conclusion}

Can communication between knowledge workers, professionals and artists be described as knowledge sharing? Some might say that it is not, that it is a mere transmission of facts and information, but not knowledge exchange.

Alavi and Leidner (2001) make an interesting observation on the hierarchy of data, information and knowledge and claim that "raw data does not exist - even the most elementary piece of "data" has already been influenced by the thought or knowledge processes that led to its identification and collection... For individuals to arrive at the same understanding of data or information, they must share a certain knowledge base" (Alavi \& Leidner, 2001, p. 109).

In the collaborative form of communication observed in this case the decision to share facts, in our view, implies that the fact was perceived by the sharer to have value to the receiver. The choice to share was influenced by the sharer's view of the difference it would make to the receiver's actions, state of mind, or attitude.

This means the fact shared was not perceived to be detached from a larger context, in which it would be knowledge.

The interviews showed that not only was knowledge being shared in the AFI case, but that it was tacit knowledge in many instances. For example, the knowledge of how a scene would look on screen is tacit in the examples quoted here. The knowledge of a certain person being unhappy in a particular day, and how to behave with that person, is tacit. In order to transfer that knowledge verbally, the sharer must explicate it. As Alavi and Leidner describe:

"information is converted to knowledge once it is processed in the mind of individuals and knowledge becomes information once it is articulated and presented in the form of text, graphics, words, or other symbolic forms." (Alavi \& Leidner, 2001, p. 109)

Therefore, when knowledge is being verbally delivered, it appears to be explicit. However, the knowledge itself, as it resided in the sharer's mind, and as it will remain in the receiver's mind after the exchange has been completed, will be tacit. The evidence confirms that knowledge being shared in the AFI is predominantly tacit.

The analysis presented in this paper allows for a number of conclusions to be drawn about knowledge sharing in the AFI.

1. The knowledge sharing is taking place within a collaborative framework, and occurs whenever information flow is observed.

2. The knowledge transfer observed in this case is predominantly tacit. We conclude that this provides strong evidence for mechanisms of tacit knowledge sharing.

3. Many of the factors previously identified as enabling the sharing of explicit knowledge are also evident in the transfer of tacit knowledge.

4. We observe that knowledge workers in the AFI are not motivated by financial reward to share their knowledge, to collaborate or to communicate. They are motivated by many 
other factors identified under the headings of Individual, Network, Relationships, Organizational and Trust. We conclude that financial reward is not a factor that enables knowledge sharing

5. The flow of information and the sharing of tacit knowledge can not be separated. Further, we also conclude that one is evidence of the other occurring.

This paper has elaborated a discussion on the knowledge sharing which occurs in the AFI, and its implications on knowledge sharing elsewhere. This research has reaffirmed the findings of previous literature that the factors previously identified in the literature do affect knowledge sharing in the AFI and mostly the affect predicted by the literature is the effect that is observed in the AFI. Secondly, analysis of the data revealed some relationships between these factors. Lastly, this case demonstrates that collaboration is a form of knowledge sharing.

This case has also illustrated many of the factors previously identified as supporting knowledge sharing. We also see evidence of a relationship between these factors. Lastly, collaboration is a form of knowledge sharing.

The study also raises more questions, a cue for further research. Firstly, we observed evidence of other factors at play in enabling and inhibiting knowledge sharing. They are not reported here, and the data is inconclusive at this stage, but there do appear to be other observable factors involved and they have not been reported elsewhere. Secondly, the results indicate that there may be a transferability of results to other industries and to other types of worker. One of the differences between AFI and organized groups of knowledge sharing is the lack of permanent infrastructure of information and communication technology connectivity among the network members. Modern organizations commonly have such infrastructure in place and therefore can use it to enhance not only the sharing of knowledge but also the capturing of it. Thirdly, we raise the question of how the various factors observed inter-relate with each other. No theory integrating the various factors, processes and types of knowledge has been described previously, and the issue is so complex that an integrating theory would prove very useful.

In conclusion, this case study proved an interesting study, especially the reliance that the participants showed on the sharing of tacit knowledge. It also allowed for the investigation of how some of these factors inter-related. The linkage between communication and sharing tacit knowledge has been established, and lastly, some interesting future research issues have been identified.

\section{References}

Alavi, M., \& Leidner, D. (2001). Review: Knowledge management and knowledge management systems: Conceptual foundations and research issues. MIS Quarterly, 25(1), 107 - 137.

Alony, I., \& Whymark, G. (2006). Developing a conceptual model for knowledge sharing. Paper presented at the Transformational Tools for $21^{\text {st }}$ Century Minds (TT21C), Rockhampton, QLD Australia.

Ardichvili, A., Page, V., \& Wentling, T. (2003). Motivation and barriers to participation in virtual knowledge-sharing communities of practice. Journal of Knowledge Management, 7(1), 64 - 77.

Argote, L. (1999). Organizational learning: Creating, retaining, and transferring knowledge. Boston: Kluwer Academic.

Argote, L., \& Ingram, P. (2000). Knowledge transfer: A basis for competitive advantage in firms. Organizational Behavior and Human Decision Processes, 82(1), 150-169.

Arthur, M., \& Defillippi, R. (1998). Live and let learn. New Zealand Management, 45(6), 60-63.

Australian Bureau of Statistics. (2003). Television, film and video production. Retrieved 19 August 2006. from 
http://www.abs.gov.au/AUSSTATS/abs@.nsf/Latestproducts/D4692FA7F7C16655CA2570DE00141 E55?opendocument.

Basit, T. N. (2003). Manual or electronic? The role of coding in qualitative data analysis. Educational Research, 45(2), 143-154.

Baum, J., \& Ingram, P. (1998). Survival-enhancing learning in the Manhattan hotel industry, 1898-1980. Management Science, 44(7), 996-1016.

Billups, S. (2003). Digital moviemaking - All the skills, techniques, and moxie you'll need to turn your passion into career $\left(2^{\text {nd }}\right.$ ed.). Studio City, CA: Michael Wiese Productions.

Blair, H. (2000). Active networking: The role of networks and hierarchy in the operation of the labour market in the British film industry. Management Research News, 20(9-11), 20-21.

Blair, H., Grey, S., \& Randle, K. (2001). Working in film - Employment in a project based industry. Personnel Review, 30(2), 170-185.

Blismas, N. G., \& Dainty, A. R. J. (2003). Computer-aided qualitative data analysis: Panacea or paradox? Building Research \& Information, 31(6), 455-463.

Bock, G., \& Kim, Y. (2002). Breaking the myths of rewards: An exploratory study of attitudes about knowledge sharing. Information Resources Management Journal, 15(2), 14-21.

Brauner, E., \& Becker, A. (2006). Beyond knowledge sharing: The management of transactive knowledge systems. Knowledge and Process Management, 13(1), 62-71.

Burt, R. (2004). Structural holes and good ideas. American Journal of Sociology, 110(2), 349-399.

Cross, R., \& Cummings, J. (2004). Tie and network correlates of individual performance in knowledgeintensive work. Academy of Management Journal. 47, 928.

Cummings, J. (2004). Work groups, structural diversity, and knowledge sharing in a global organization. Management Science, 50(3), 352-364.

Cunningham, S. (2002). From Cultural to creative industries: Theory, industry, and policy implications. Retrieved from http://www.creativeindustries.qut.com/research/cirac/documents/ARC_Linkages_4.pdf

Daskalaki, M., \& Blair, H. (2002). 'Knowing' as an activity: Implications for the film industry and semipermanent work groups. Paper presented at the Organisational Knowledge, Learning and Capabilities Athens Conference, Athens.

DeNardo, A. M., \& Levers, L. L. (2002). Using NVivo to analyze qualitative data. Retrieved 15th August, 2005, from http://www.education.duq.edu/institutes/PDF/papers2002/DeNardo\&Levers.pdf

Dyer, J., \& Nobeoka, K. (2000). Creating and managing a high-performance knowledge-sharing network: The Toyota case. Strategic Management Journal, 21(3), 345 - 367.

Emery, F. E., \& Trist, E. L. (1965). The causal texture of organisational environments. Human Relations, $18,21-32$.

Fairfax. (2003, 17Apr2003). It's a casual affair. Retrieved 05Sep2003, from http://www.alliance.org.au/leadstory/2003/fairfax.htm

Glaser, B. G. (1978). Theoretical sensitivity: Advances in the methodology of grounded theory. Mill Valley, CA: Sociology Press.

Glaser, B. (2001). The grounded theory perspective: Conceptualization contrasted with description. Mill Valley, CA: Sociology Press.

Glaser, B., \& Strauss, A. (1967). The discovery of grounded theory: Strategies for qualitative research. New York: Aldine.

Hansen, M. (1999). The search-transfer problem: The role of weak ties in sharing knowledge across organization subunits. Administrative Science Quarterly, 44(1), 82-111. 
Hansen, M. (2002). Knowledge networks: Explaining effective knowledge sharing in multiunit companies. Organization Science, 13(3), 232.

Jacka, E. (1997). Film. In S. Cunningham \& G. Turner (Eds.), The media in Australia - Industries, texts, audiences ( $2^{\text {nd }}$ ed), (pp. 227-244). St Leonards, NSW: Allen \& Unwin.

Jones, M. (2005). 'Lights... Action... Grounded Theory': Developing an understanding for the management of film production. Rhyzome, 1(1), 163-173.

Kilduff, M., \& Tsai, W. (2003). Social networks and organizations: Sage Publications.

Lesser, E., \& Storck, J. (2001). Communities of practice and organizational performance. IBM Systems Journal, 40(4), 831-841.

Levin, D., \& Cross, R. (2004). The strength of weak ties you can trust: The mediating role of trust in effective knowledge transfer. Management Science, 50(11), 1477-1490.

Lichtenstein, S., \& Hunter, A. (2006). Toward a receiver-based theory of knowledge sharing. International Journal of Knowledge Management, 2(1), 19-35.

Majchzak, A., Rice, R., King, N., Malhotra, A., \& Ba, S. (2000). Computer-mediated inter-organizational knowledge-sharing: Insights from a virtual team innovating using a collaborative tool. Information Resources Management Journal, 13(1), p.44-53.

Markus, L. M. (2001). Toward a theory of knowledge reuse: Types of knowledge reuse situations and factors in reuse success. Journal of Management Information Systems, 18(1), 57.

Mayer, R., Davis, J., \& Schoorman, F. (1995). An integration model of organizational trust. Academy of Management, 20(3), 709-734.

McAllister, D. (1995). Affect- and cognition-based trust as foundations for interpersonal cooperation in organizations. Academy of Management Journal, 38(1), 24-59.

Nonaka, I. (1994). A dynamic theory of organizational knowledge creation. Organization science (Providence, R.I.), 5(1), 14-37.

Owen-Smith, J., \& Powell, W. (2004). Knowledge networks as channels and conduits: The effects of spillovers in the Boston biotechnology community. Organization Science, 15(5), 5-21.

Perrow, C. (1967). A framework for the comparative analysis of organizations. American Sociological Review, 32, 194-208.

Powell, W., Koput, K., \& Smith-Doerr, L. (1996). Interorganizational collaboration and the locus of innovation: Networks of learning in biotechnology, Administrative Science Quarterly, 41(1), 116-145.

QSR International Pty Ltd. (2002). QSR NVivo (Version 2.0.161).

Reagans, R., \& McEvily, B. (2003). Network structure and knowledge transfer: The effects of cohesion and range. Administrative Science Quarterly, 48(2), 240-268.

Richards, T. (2002). An intellectual history of NUD*IST and NVivo. International Journal of Social Research Methodology, 5(3), 199-214.

Starkey, K., Barnatt, C., \& Tempest, S. (2000). Beyond networks and hierarchies: Latent organizations in the U.K. television industry. Organization Science, 11(3), 299-305.

Stenmark, D. (2000). Leveraging tacit organizational knowledge. Journal of Management Information Systems, 17(3), 9 - 24.

Terry, J., \& Standing, C. (2004). The value of user participation in E-Commerce systems development. Informing Science Journal, 7, 31-45. Available at http://inform.nu/Articles/Vol7/v7p031-045-216.pdf

Tesch, R. (1990). Qualitative research: Analysis types and software tools. New York: Falmer Press. 


\section{Biographies}

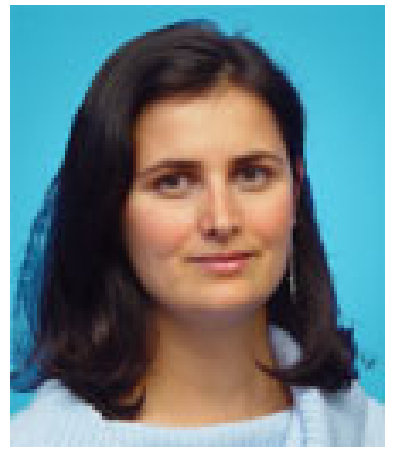

Irit Alony (BCSc; Grad.Cert. (Comp Sc.); MIS) has been an academic teaching and researching in areas of information systems, knowledge management, and communication and culture for two years at Central Queensland University. Irit has developed research interests in the following areas: knowledge sharing, tacit knowledge, creative industries, knowledge management and strategic use of information systems. Irit is also developing research strengths in areas of qualitative analysis. Irit is involved in a major research project exploring competitive analysis in the Australian Marine Industry.

Irit is currently engaged in the early stages of her $\mathrm{PhD}$ researching knowledge sharing.

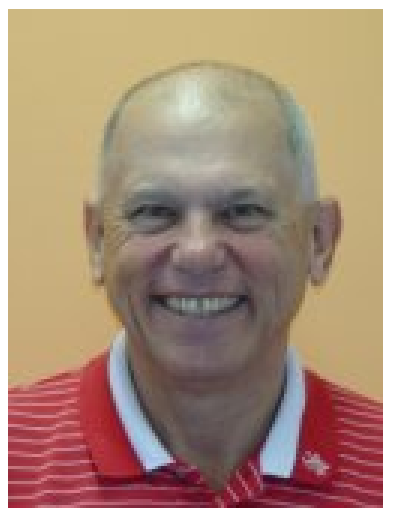

Greg Whymark is Associate Professor in Information Systems at the faculty of Business and Informatics at Central Queensland University (CQU), Rockhampton, Queensland, Australia. He is head of the Group SolutionS Research Group which is interested in how people and technology work together. The group occupies the old Supreme Court building in Rockhampton City, and has two meeting rooms with group support system technology. He earned his BSc from the university of Queensland, MSc from Wollongong University, and PhD from the University of New South Wales, and has six research students working on aspects of IS management and knowledge management. His research interests include activity theory, knowledge management and management support systems.

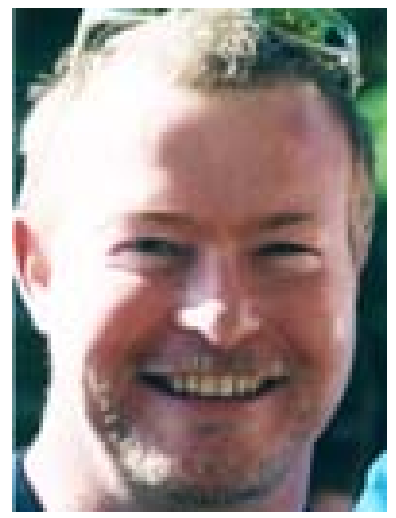

Michael Jones (BComm (hons), PhD.) has been an academic teaching and researching in areas of organisation, business and management for eight years. Michael has developed research interests in the following areas: organisational psychology and behaviour - looking at commitment and motivation and group dynamics. Michael is also developing research strengths in areas of qualitative analysis and has written several papers on various qualitative methodologies and methods. Michael is also interested in research areas such as knowledge management and organisational learning. Michael is also a co-investigator on a major research project explore competitive analysis in the Australian Marine Industry.

Michael is a member of the Australia and New Zealand Academy of Management, the Australian Human Resources Institute, and the Industrial Relations Society of Australia. 